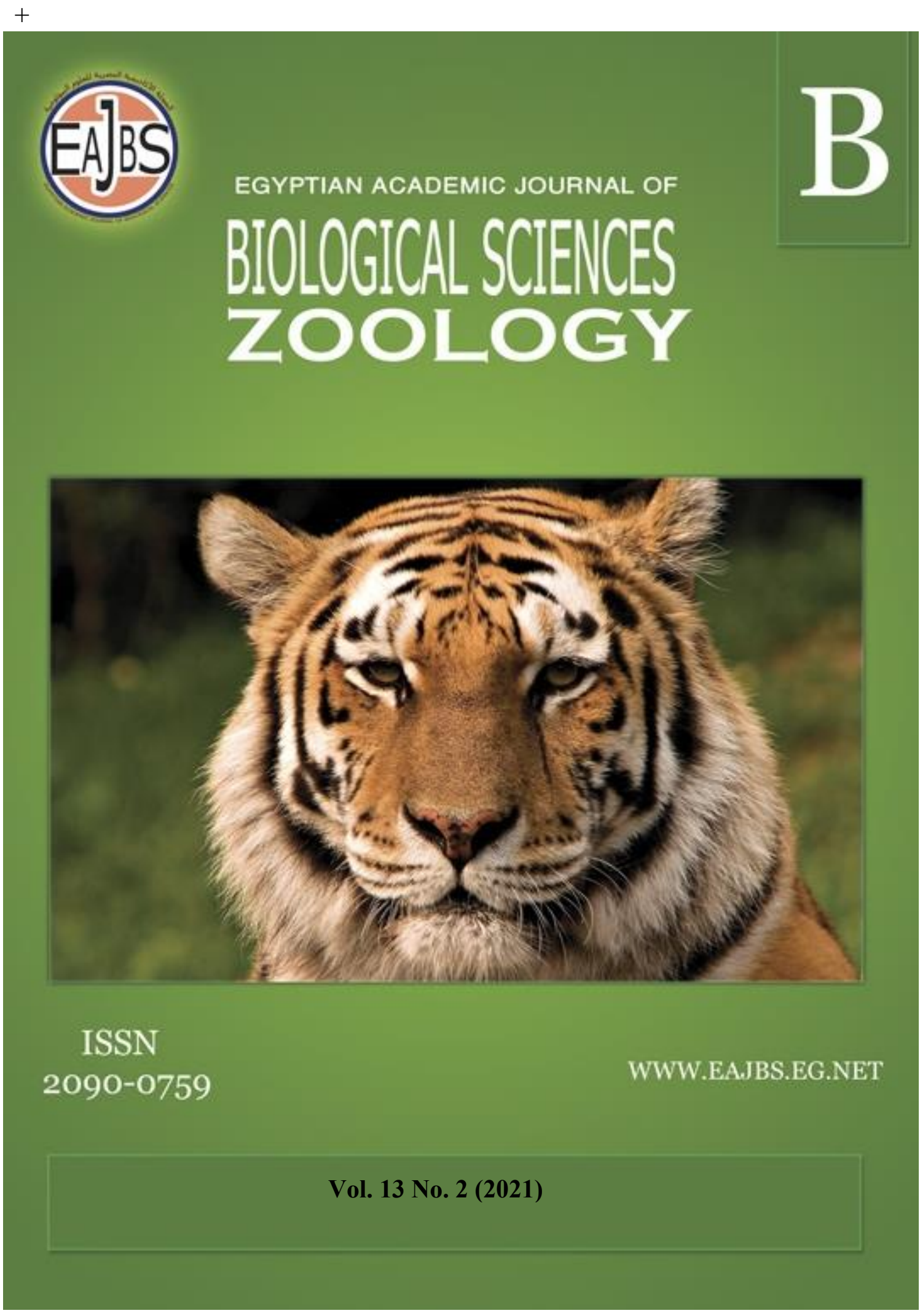

www.eajbs.eg.net 
Egypt. Acad. J. Biolog. Sci., 13(2): 197-206 (2021)

Egyptian Academic Journal of Biological Sciences

B. Zoology

ISSN: $2090-0759$

http://eajbsz.journals.ekb.eg/

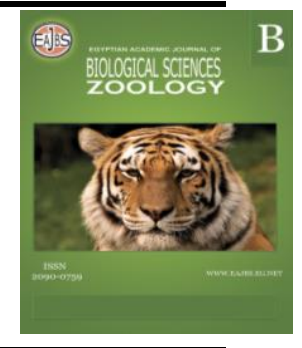

\title{
Guard Hair Morphology of Cercopithecidae Family in Omo Forest Reserve, Ogun State, Nigeria
}

\author{
T.R. Olugbebi ${ }^{1}$, F. Olaleru ${ }^{1,2 *}$, M.I. Fasona ${ }^{1}$ and Q.O. Omoregie ${ }^{2}$ \\ $1^{-}$Department of Zoology, Faculty of Science, University of Lagos, Nigeria \\ 2-TETFund Centre of Excellence for Biodiversity Conservation and Ecosystem \\ Management, University of Lagos, Nigeria
}

E.mail*: folaleru@unilag.edu.ng

\begin{abstract}
ARTICLE INFO
Article History

Received:30/10/2021

Accepted:2/12/2021

Keywords:

Guard hair, hair

morphology,

medullary cortex,

medullary index,

shaft diametre.

ABSTRACT

Apart from its use for protection, temperature regulation, and identification of species, mammalian hair can be used in forensic biology through morphological analysis to identify trafficked endangered wildlife. This study determined the morphological characteristic of dorsal guard hairs of four species of Cercopithecidae family obtained from hunters in Omo Forest Reserve, Ogun State, Nigeria. These were mona monkey (Cercopithecus mona), putty-nosed monkey (Cercopithecus nictitans), red-capped mangabey (Cercocebus torquatus), and whitethroated monkey (Cercopithecus erythrogaster). Data on qualitative and quantitative morphological characteristics of hair samples were obtained and analysed using standard methods. The qualitative features determined were scale patterns and medulla type; while the quantitative were scale length and width, shaft diametre $(\mu \mathrm{m})$, medulla diametre and medulla index and fraction. $C$. mona had the highest values in shaft (387.00 \pm 75.38$)$ and medullary $(226.00 \pm 59.73)$ diametres, scale length $(218.76 \pm 60.29)$ and width $(725.76 \pm 155.91)$, and medullary index $(0.58 \pm 0.13)$ and fraction $(58.4 \pm 12.60)$. All the quantitative hair morphologies of the four species were significantly different $(\mathrm{P} \leq 0.05)$ except scale length (which was significant at $\mathrm{P} \leq 0.07$ ). A post hoc test showed that the medullar diametre of $C$. mona was significantly different $(\mathrm{P} \leq .003)$ from the other species. The medullary diametre of $C$. nictitans was significantly different $(\mathrm{P} \leq 0.05)$ from $C$. torquatus. The medullary index of $C$. mona was significantly different from that of $C$. nictitans $(\mathrm{P} \leq 0.017), C$. torquatus $(\mathrm{P} \leq 0.001)$, and $C$. erythrogaster $(\mathrm{P} \leq 0.003)$. The differences observed in the morphological features of the sampled hairs could be used in species identification and a database for any trafficked member of these four species from Nigeria.
\end{abstract}

\section{INTRODUCTION}

Mammalian hairs do not only serve the unique functions of protecting the skin from rough surfaces, piercing objects like thorns, and harsh weather through thermoregulation, but also play a vital role in species identification (Sari and Arpacik, 2018). The mammalian epidermal exoskeleton has a distinctive specialized anatomic 
structure that consists of cells that are placed in three concentric layers, viz: cuticle, cortex, and medulla. The cortex gives hair its colour, the cuticle is useful to identify species and the medulla is the central canal. The morphological configuration of these layers varies between humans and animals, and among animal species. This variation can be used to identify species through various methods of hair analyses (Bhat et al. 2014).

Two methods that could be reliably used for the identification of mammals using hair are molecular analysis and microscopic examination (Linacre and Tobe, 2011). Molecular analysis is the standard for species identification due to its high accuracy and sensitivity. Hair morphology could be used for identification at the species level. The long time, high cost, and destructive nature of molecular analysis makes hair microscopy a viable alternative (Kitpipit and Thanakiatkrai, 2013). Microscopic hair identification is a non-invasive, simple, and economical method applied in scientific studies to identify mammal species. Based on morphological characteristics of the hair cuticle scales and medulla, some hairs and animal species can be distinguished with ease. This makes the morphological assessment of hairs an important method useful in forensic science (Sato, 2002; Sato et al., 2006). The scientific comparison of hair morphology as a forensic technique like fingerprint, handwriting samples, and firearms is well established (Houck et al. 2004).

The morphological features of hair easily differentiate mammalian species. This has helped in the monitoring and population determination of specific mammal species (Yasser et al. 2018). The presence and types of elusive mammals could be easily determined through the hair morphological features. Hair in the faecal sample of an animal could also be used for its mastofaunistic inventories and dietary analysis (Souza and Azevedo, 2021). Thus, hair morphology has been quite useful in conservation management projects since it could be used for population genetics, dietary composition of mammals, and habitat occupancy (Cornally and Lawton 2016).

There are numerous studies on hair morphology of different wildlife (buffalo, deer, hare, howler monkey, mona monkey. hyena, leopard, lion, tiger, jaguar, puma and wild goat) and domestic (cow, goat, sheep) mammals from different parts of the world. Hair from different parts of the animals' bodies studied has shown to be valuable for forensic and zoological purposes, and dietary ecology of predators (Verma and Joshi, 2012; Bhat et al., 2014; Farag et al., 2015; Cornally and Lawton, 2016; Sar1 and Arpacik, 2018; Tremori et al., 2018; Olaleru et al., 2020, Souza and Azevedo. 2021). Some of these studies showed cannibalism and infanticide in chimpanzees (Walker et al., 2018). Hair morphology characteristics could provide information on the identity of animals (Tridico et al., 2015), non-human primates inclusive have been used to identify hairs of predators and prey from scat samples (Souza and Azevedo, 2021).

The scientific use of hair morphology for the identification of wildlife in Nigeria seems obscure. Qualitative and quantitative data on the hair morphology of mona monkey was reported by Olaleru et al. (2020). Hair morphologies for putty-nosed monkey, red-capped mangabey, and white-throated monkey has not been reported. This study seeks to bridge this gap in knowledge. The aim of this study was to determine, compare, and contrast the morphological characteristics of the guard hairs of four species of the Cercopithecidae family: mona monkey (Cercopithecus mona), putty-nosed monkey (Cercopithecus nictitans), red-capped mangabey (Cercocebus torquatus), and white-throated monkey (Cercopithecus erythrogaster) that inhabit the Omo Forest Reserve, Ogun State, Nigeria. The results would serve as database and hair morphology guide in identifying these species, and reporting evidence. 


\section{MATERIALS AND METHODS}

\section{Study Area:}

This study was conducted in Omo Forest Reserve (OFR) and the University of Lagos. Hair samples of four species of the Cercopithecidae family found in OFR (Fig. 1) were collected and taken to the University for laboratory analyses. The Reserve which covers an area of $1325 \mathrm{~km}^{2}$ is located in Ogun State, South-Western part of Nigeria. It has a mean annual rainfall of about $2050 \mathrm{~mm}$ and a mean monthly temperature of about $27^{\circ} \mathrm{C}$. Vegetatively, it was a lowland tropical rainforest. This has been reduced to secondary forest, thickets and farmlands of annual and perennial crops, with the exception of some parts of the Reserve (Adedeji and Adeofun, 2014).

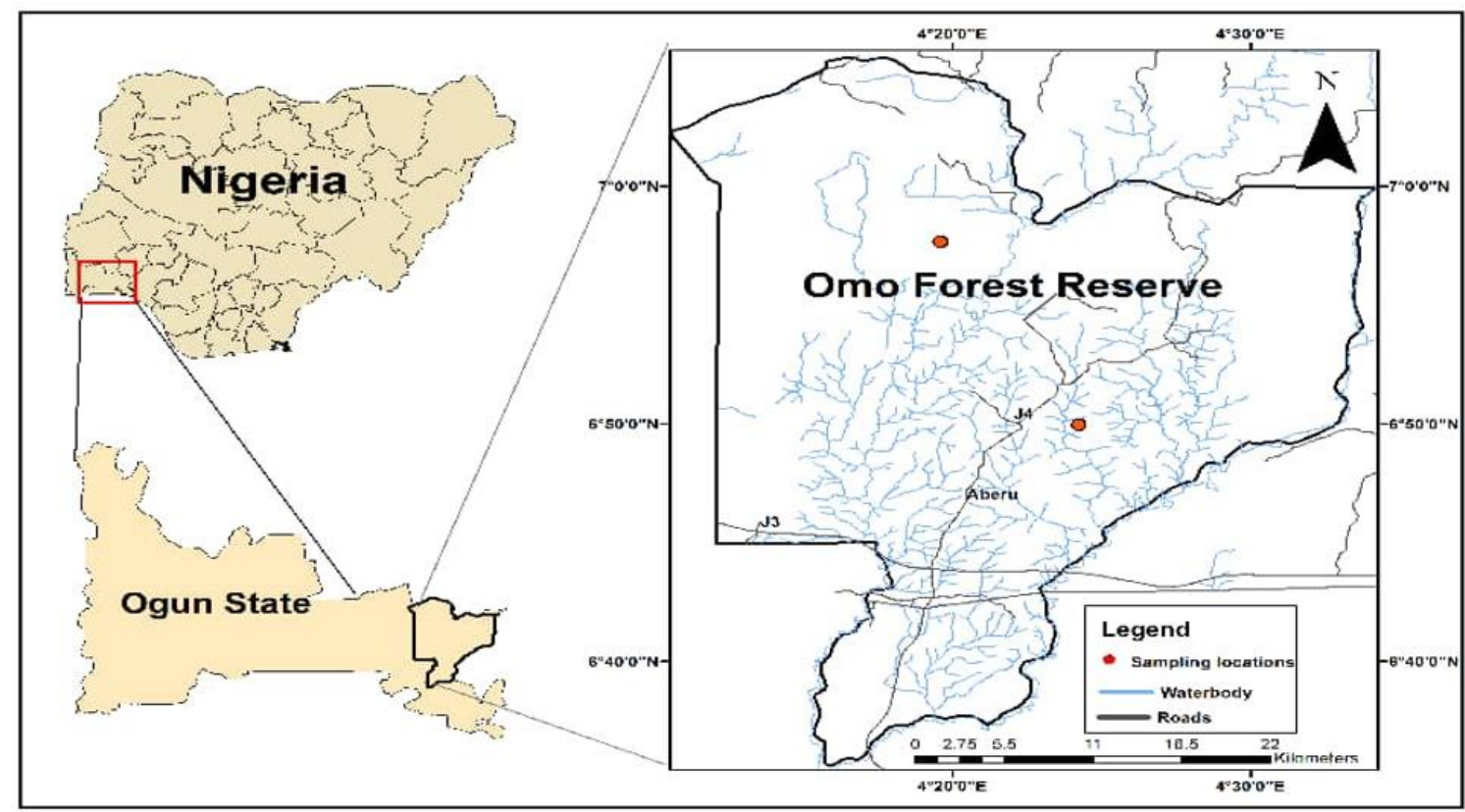

Fig. 1: Map of Omo Forest Reserve with sampling locations.

\section{Hair Sample Preparation For Microscopic Examination:}

The hair samples of the four species of the Cercopithecidae family were collected from hunters found in the support zone of the Reserve. These were placed in labelled paper envelopes immediately after collection, and then placed in zip-lock bags with silica gel and stored at room temperature until morphological analysis was carried out. The labels indicated the focal species, name of the collector, date, and location of collection.

Before use, the hairs were cleaned and degreased using ethanol at $70 \%$ to remove dirt and air-dried prior to further analysis (Verma and Joshi, 2012; Priyanka et al., 2017). Following the method of Crocker (1998), hair samples were viewed and analysed using a light microscope equipped with a digital camera and connected to the image analyser. For each hair sample, the shaft, medulla, and cuticular scale pattern were determined and photomicrographs were taken. For medulla assessment, glycerin was put on the slide and the hair was placed on it, then a cover-slip was put to hold it firmly. The medulla type was determined when viewed at $10 \mathrm{x}$ magnification using light microscope.

The hair was returned into the ethanol for further cleaning and degreasing. The scale casts were assessed using the rapid clear nail polish method described by Houck et al. (2004). Clear nail polish was dropped on a clean microscope slide. It was allowed to 
set for one or two minutes when the fluidity was reduced. Fine pointed forceps was used to place one strand of hair on the nail polish. The slides were put away to dry in a dustfree place for about five minutes. When the clear nail polish had completely dried, the hair was removed with fine forceps leaving the scale covering on the slide. The scale pattern was then observed under light microscope at a magnification of $x 40$.

\section{Morphological Characteristics: \\ Qualitative Characteristics:}

The whole hair mounts of five randomly selected samples were used for determining the qualitative characteristics of the four species of the Cercopithecidae family. The qualitative hair characteristics examined were cuticular scale features (margin distance and type, and pattern) and medulla type (pattern and structure). Characteristic features were recorded based on the morphology of the hair cuticle scales, and medulla. Hair keys as listed in Yasser et al. (2018) and Cornally and Lawton (2016) were used as guide.

\section{Quantitative Morphology Characteristics:}

The quantitative morphological characteristics of the hairs of the four species of the Cercopithecidae family were calculated according to Kitpipit and Thanakiatkrai (2013).For whole-mount specimens, four quantitative variables were determined. These were hair diametre $(\mu \mathrm{m})$, medullary diametre $(\mu \mathrm{m})$, medullary index, and medullary fraction. Hair and medullary diametres were measured using a calibrated micrometre in the eyepiece. Medullary index was calculated as follows:

Medullary index $=\frac{\text { Diametre of medulla }}{\text { Diametre of hair }}$ OR $\frac{\text { Medulla thickness }}{\text { Hair thickness }} \quad$ (Sahajpal et al., 2008). Medullary fraction was determined as percentage of medullary index, viz:

Medullary fraction $=\frac{\text { Diametre of medulla }}{\text { Diametre of hair }} \times$ (Kitpipit and Thanakiatkrai 2013).

For scale-cast specimens, the numerical features determined were scale width and length $(\mu \mathrm{m})$. These were measured from the cuticle's scale. They were randomly selected using a calibrated micrometer in the eyepiece.

\section{Data Analysis:}

Microsoft Excel and the Statistical Package for Social Sciences (SPSS Version 20) were used respectively for descriptive and inferential analysis of the data. The mean and standard deviation of the quantitative features such as medullary and shaft diametres, scale length and width. Analysis of variance (ANOVA) was used to determine whether there were statistical differences in the quantitative variables of the four species of the Cercopithecidae family in OFR. A post hoc of statistically significant means $(\mathrm{P} \leq 0.05)$ was using least significant difference (LSD).

\section{RESULTS}

Plate 1 showed the photomicrograph of the different scale and medulla features in the four species of the Cercopithecidae family, whose respective descriptive summary were shown in Table 1. A continuous medulla pattern was common to all species. All the species except Cercopithecus erythrogaster had distant scale margins, and all had imbricate scale pattern except Cercocebus torquatus. The scale margin and medulla structure were respectively crenate and amorphous in both Cercopithecus mona and Cercopithecus nictitans. These features were respectively smooth and uniserial in both Cercocebus torquatus and Cercopithecus erythrogaster. 


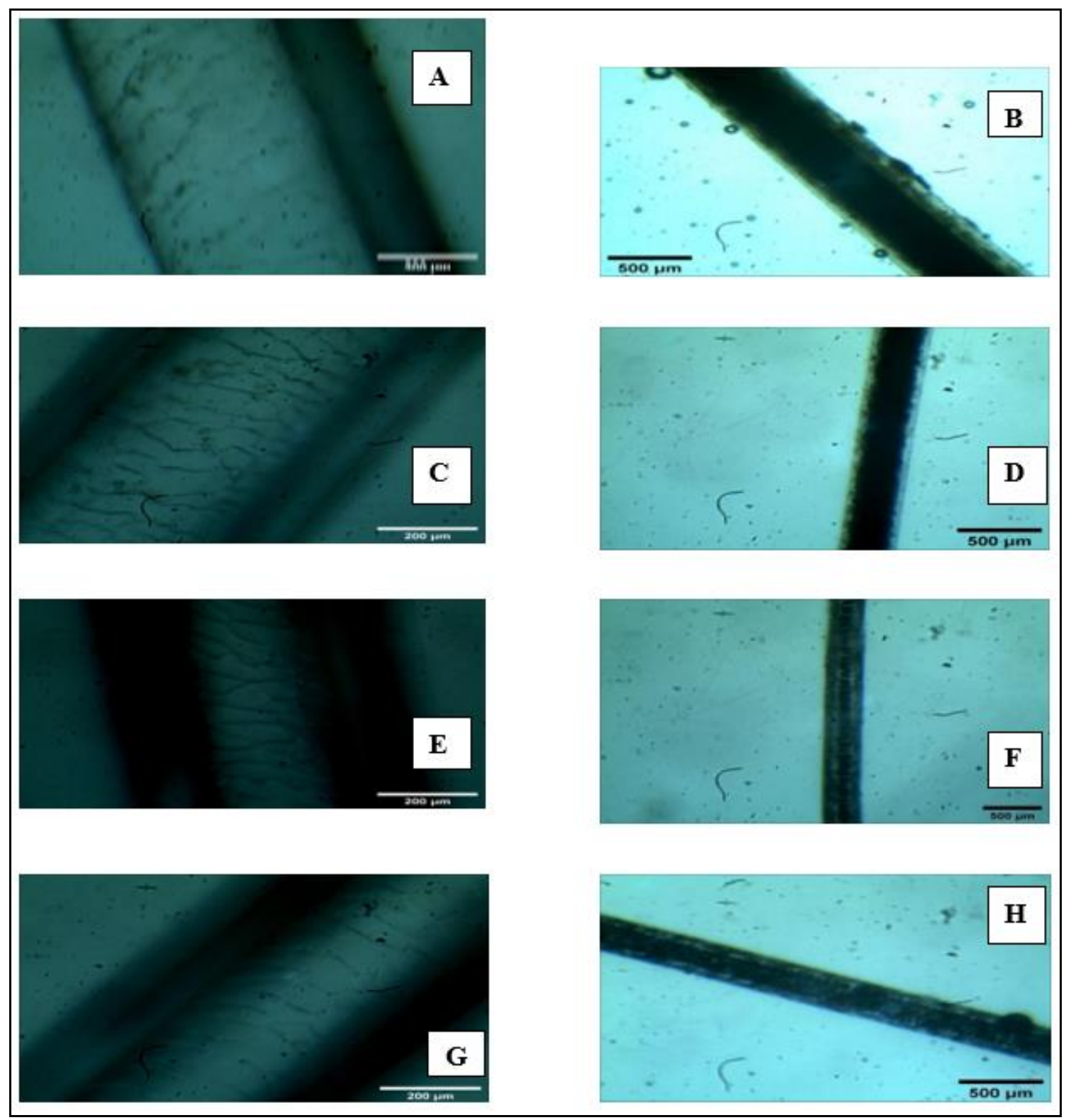

Plate 1: Hair scale pattern and medulla of the four species of the Cercopithecidae family in Omo Forest Reserve.

$\mathrm{A}$ and $\mathrm{B}=$ Respective scale pattern and medulla of Cercopithecus mona hair $\mathrm{C}$ and $\mathrm{D}=$ Respective scale pattern and medulla of Cercopithecus nictitans hair $\mathrm{E}$ and $\mathrm{F}=$ Respective scale pattern and medulla of Cercocebus torquatus hair $\mathrm{G}$ and $\mathrm{H}=$ Respective scale pattern and medulla of Cercopithecus erythrogaster hair

Table 1: Qualitative characteristics of four species of the Cercopithecidae family in Omo Forest Reserve

\begin{tabular}{|l|l|l|l|l|l|}
\hline Features & \multicolumn{3}{|c|}{ Scale features } & \multicolumn{2}{c|}{ Medulla features } \\
\hline Sample & Margin distance & Margin type & Pattern & Pattern & Structure \\
\hline MH & Distant & Crenate & Imbricate & Continuous & Amorphous \\
\hline PH & Intermediate & Crenate & Imbricate & Continuous & Amorphous \\
\hline RH & Distant & Smooth & Coronal & Continuous & Uniserial \\
\hline WH & Distant & Smooth & Imbricate & Continuous & Uniserial \\
\hline
\end{tabular}

MH = Mona monkey's hair, PH = Putty-nosed monkey's hair, RH = Red-capped monkey's hair, WH = White-throated monkey's hair. 
Table 2 showed the mean and standard deviation of the medullar (diametre, index, and fraction), shaft diameter, and cuticular scale (length and width) of the four species. The guard hair of $C$. mona had the highest values in all the features. This was followed by $C$. nictitans and $C$. erythrogaster, while Cercocebus torquatus had the least.

Table 2: Mean and standard deviation of hair morphological characteristics of four species of the Cercopithecidae family in Omo Forest Reserve.

\begin{tabular}{|l|l|l|l|l|l|l|l|}
\hline Sample & $\mathbf{N}$ & $\begin{array}{c}\text { Medullary } \\
\text { diametre }(\boldsymbol{\mu m})\end{array}$ & $\begin{array}{c}\text { Medulla } \\
\text { ry index }\end{array}$ & $\begin{array}{c}\text { Medullary } \\
\text { fraction }\end{array}$ & $\begin{array}{c}\text { Shaft } \\
\text { diametre }(\boldsymbol{\mu m})\end{array}$ & $\begin{array}{c}\text { Scale length } \\
(\boldsymbol{\mu m})\end{array}$ & $\begin{array}{c}\text { Scale Width } \\
(\boldsymbol{\mu m})\end{array}$ \\
\hline $\mathrm{MH}$ & 5 & $226.00 \pm 59.73$ & $0.58 \pm 0.13$ & $58.4 \pm 12.60$ & $387.00 \pm 75.38$ & $218.76 \pm 60.29$ & $725.76 \pm 155.91$ \\
\hline PH & 5 & $107.5 \pm 75.87$ & $0.32 \pm 0.22$ & $32.40 \pm 22.46$ & $339.0 \pm 174.48$ & $151.73 \pm 15.53$ & $642.93 \pm 107.59$ \\
\hline RH & 5 & $32.00 \pm 5.70$ & $0.12 \pm 0.03$ & $12.20 \pm 3.27$ & $276.00 \pm 86.99$ & $150.82 \pm 12.30$ & $439.25 \pm 72.25$ \\
\hline WH & 5 & $47.00 \pm 42.23$ & $0.24 \pm 0.17$ & $23.80 \pm 16.69$ & $185.36 \pm 49.88$ & $202.08 \pm 65.52$ & $458.68 \pm 90.87$ \\
\hline
\end{tabular}

Note: $\mathrm{MH}=$ Mona monkey's hair, $\mathrm{PH}=$ Putty-nosed monkey's hair, $\mathrm{RH}=$ Red-capped monkey's hair, WH= White-throated monkey's hair.

Table 3 showed ANOVA of the quantitative morphological characteristics of the four species of the Cercopithecidae family in OFR. The scale lengths of the four species of the Cercopithecidae family were not significantly different at $(P \geq 0.05)$. All the other quantitative morphological characteristics were significantly different $(\mathrm{P} \leq 0.05)$ between the four species.

Table 3: Analysis of variance of the morphological characteristics of four species of the Cercopithecidae family in Omo Forest Reserve.

\begin{tabular}{|c|c|c|c|c|c|}
\hline \multicolumn{2}{|c|}{ Morphological characteristics } & df & Mean Square & $\mathbf{F}$ & Sig. \\
\hline \multirow{3}{*}{$\begin{array}{l}\text { Medullary } \\
\text { Diametre }\end{array}$} & Between Groups & 3 & 38876.98 & 13.979 & $0.000 * * *$ \\
\hline & Within Groups & 16 & 2784.83 & & \\
\hline & Total & 19 & & & \\
\hline \multirow[t]{3}{*}{ Medullary Index } & Between Groups & 3 & 0.193 & 8.091 & $0.002 * *$ \\
\hline & Within Groups & 16 & 0.024 & & \\
\hline & Total & 19 & & & \\
\hline \multirow{3}{*}{$\begin{array}{l}\text { Medullary } \\
\text { Fraction }\end{array}$} & Between Groups & 3 & 1926.733 & 8.091 & $0.002 * *$ \\
\hline & Within Groups & 16 & 238.125 & & \\
\hline & Total & 19 & & & \\
\hline \multirow[t]{3}{*}{ Shaft Diametre } & Between Groups & 3 & 37945.83 & 3.287 & $0.048 * *$ \\
\hline & Within Groups & 16 & 11545.23 & & \\
\hline & Total & 19 & & & \\
\hline \multirow[t]{3}{*}{ Scale Length } & Between Groups & 3 & 6063.525 & 2.915 & 0.066 \\
\hline & Within Groups & 16 & 2080.150 & & \\
\hline & Total & 19 & & & \\
\hline \multirow[t]{3}{*}{ Scale Width } & Between Groups & 3 & 98372.282 & 7.972 & $0.002 * *$ \\
\hline & Within Groups & 16 & 12339.980 & & \\
\hline & Total & 19 & & & \\
\hline
\end{tabular}

Note: $* * *=\mathrm{P} \leq 0.001, * *=\mathrm{P} \leq 0.01, *=\mathrm{P} \leq 0.05$

The mean separation of medullary diametre, index, and fraction, shaft diametre, and scale length, and width of the four species of the Cercopithecidae family is shown in Table 4. There was a significant difference $(\mathrm{P} \leq 0.003)$ in medullary diametre between $C$. mona and the three other species. The medullary diametre of $C$. nictitans was also significantly different $(\mathrm{P} \leq 0.05)$ from that of Cercocebus torquatus. 
The medullary index of $C$. mona was significantly different $(\mathrm{P}<0.017)$ from the other species. That of $C$. nictitans was slightly significantly different $(\mathrm{P}<0.055)$ from Cercocebus torquatus. There was a similar pattern of significant differences in the medullary fraction of the species to that of the medullary index. In shaft diametre, $C$. mona was significantly different $(\mathrm{P}<0.009)$ from $C$. erythrogaster, while $C$. nictitans was significantly different $(\mathrm{P} \leq 0.05)$ from $C$. erythrogaster. The scale length of $C$. mona indicated significant differences $(\mathrm{P} \leq 0.05)$ to those of $C$. nictitans and Cercocebus torquatus. The scale width of $C$. mona was different from $C$. erythrogaster and Cercocebus torquatus.

Table 4: Least Significant Difference for medullary (diametre, index, and fraction), shaft diametre, and scale (length and width) of the four species of the Cercopithecidae family in Omo Forest Reserve.

\begin{tabular}{|c|c|c|c|c|c|}
\hline $\begin{array}{c}\text { Dependent } \\
\text { Variable }\end{array}$ & (I) Species & (J) Species & Mean Difference (I-J) & Std. Error & Sig. \\
\hline \multirow{4}{*}{$\begin{array}{l}\text { Medullary } \\
\text { Diametre }\end{array}$} & \multirow[t]{3}{*}{ C. mona } & C. nictitans & 118.50 & 33.38 & $0.003 * *$ \\
\hline & & Cercocebus torquatus & 194.00 & 33.38 & $0.000^{* * *}$ \\
\hline & & C. erythrogaster & 179.00 & 33.38 & $0.000 * * *$ \\
\hline & C. nictitans & Cercocebus torquatus & 75.50 & 33.38 & $0.038^{*}$ \\
\hline \multirow{4}{*}{$\begin{array}{l}\text { Medullary } \\
\text { Index }\end{array}$} & \multirow{3}{*}{ C. mona } & C. nictitans & 0.26 & 0.098 & $0.017 * *$ \\
\hline & & Cercocebus torquatus & 0.46 & 0.098 & $0.000^{* * *}$ \\
\hline & & C. erythrogaster & 0.35 & 0.098 & $0.003 * *$ \\
\hline & C. nictitans & Cercocebus torquatus & 0.20 & 0.098 & $0.055^{*}$ \\
\hline \multirow{4}{*}{$\begin{array}{l}\text { Medullary } \\
\text { Fraction }\end{array}$} & \multirow[t]{3}{*}{ C. mona } & C. erythrogaster & 34.60 & 9.76 & $0.003 * *$ \\
\hline & & C. nictitans & 26.00 & 9.76 & $0.017 * *$ \\
\hline & & Cercocebus torquatus & 46.20 & 9.76 & $0.000^{* * *}$ \\
\hline & C. nictitans & Cercocebus torquatus & 20.20 & 9.76 & $0.055^{*}$ \\
\hline \multirow{2}{*}{$\begin{array}{l}\text { Shaft } \\
\text { diametre }\end{array}$} & C. mona & C. erythrogaster & 201.64 & 67.96 & $0.009 * * *$ \\
\hline & C. nictitans & C. erythrogaster & 153.64 & 67.96 & $0.038^{* *}$ \\
\hline \multirow{2}{*}{$\begin{array}{l}\text { Scale } \\
\text { Length }\end{array}$} & \multirow{2}{*}{ C. mona } & C. nictitans & 67.03 & 28.85 & $0.034 * *$ \\
\hline & & Cercocebus torquatus & 67.95 & 28.85 & $0.032 * *$ \\
\hline \multirow[t]{4}{*}{ Scale Width } & \multirow[t]{2}{*}{ C. mona } & Cercocebus torquatus & 286.51 & 70.26 & $0.001 * * *$ \\
\hline & & C. erythrogaster & 267.08 & 70.26 & $0.002 * *$ \\
\hline & \multirow[t]{2}{*}{ C. nictitans } & Cercocebus torquatus & 203.68 & 70.26 & $0.010^{* *}$ \\
\hline & & C. erythrogaster & 184.25 & 70.26 & $0.018 * *$ \\
\hline
\end{tabular}

Note: Significant at $* * *=\mathrm{P} \leq 0.001, * *=\mathrm{P} \leq 0.01, *=\mathrm{P} \leq 0.05$

\section{DISCUSSION}

Continuous medullary pattern was the only qualitative feature that was common to all species studied. This could imply that members of the Cercopithecidae family have this common feature. This continuous medullary pattern was also reported in brown howler monkey (Alouatta guariba) in Brazil (Tremori et al., 2018). Similarity in some qualitative characteristics pattern among all the species implied that qualitative characteristics only has limitations in distinguishing the four studied species of the Cercopithecidae family.

The quantitative characteristics are crucial in distinguishing the species. The significant difference in medulla structure between the four species confirms that medulla structure is key for the identification of species at the family level (Sari and Arpacik, 2018). This reflects the uniqueness of each species. Medullar diametre, index, and fraction, shaft diametre, and cuticular scale width of the four species were ideal metrics to differentiate the four species. The significant differences were in agreement 
with the result Kitpipit and Thanakiatkrai (2013) found in tiger hair from Songkhla Zoo and Chiang Mai Zoo, Thailand.

The medullary diametre is a useful parameter to differentiate between animal hairs. The medullary diametre of mona monkey varied significantly when compared with other studied species. Significant differences in medullary diametre could be found even in an individual mammalian hair depending on the region of the body where the hair was sampled. Sheela et al. (2018) reported significant differences in the medullary diametre of hair obtained from different regions of blackbucks (Antelope cervicapra) from Nehru Zoological Park, Hyderabad. Aris and George (2008) also reported a significant difference in the medullary diametre of goat hair and sheep wool.

The results of the medullary index are in agreement with Deedrick and Koch (2004) who stated that the medulla of hair is also valuable in identifying species. The medullary index of animals is greater than that of humans. According to Chernova (2003), the differences in medullary index observed between animals could be as a result of structural and functional adaptation because the medulla is related to the thermal insulation of hair coat of different animals.

Hair shaft diametre can vary between $10-250 \mu \mathrm{m}$, this is influenced by the animal metabolic and nutrient status and indirectly play a role in the variability of the shaft diametre observed in different animal species (Farag et al., 2015).

Morphological identification of hair shafts is proven to be an inexpensive way of distinguishing species (Carlos et al., 2017). It is also proven to be useful tool in monitoring populations in their natural habitat (Chiron et al., 2018; Phoebus et al., 2020) and for investigating the illegal trafficking of wildlife (Tremori et al., 2018).

\section{CONCLUSION}

This study provided a first-hand step towards the preparation of a reference database for the identification of these four primate species of the Cercopithecidae family in Omo Forest Reserve using guard hair. The results presented a clear comparative analysis between the hairs of the studied species. The standard procedure was easy, cheaper, faster, and relatively reliable for use in situations where quick assessments on trafficked wildlife need to be made, and the only evidence are hair samples. The findings from this research can serve as a reference for endangered populations like Cercocebus torquatus and Cercopithecus erythrogaster. The hair samples could be obtained non-invasively without disturbing them. This result could aid conservationists in monitoring the presence, population dynamics, animal movement and their ecological influences. Hair morphology can be carried out before molecular analysis to eliminate nonfocal species. More of these guard hair studies on the same species from other forest habitats need to be conducted to establish their standard qualitative and quantitative morphological patterns.

\section{REFERENCES}

Adedeji, O.H. and Adeofun, C.O. (2014). Spatial Pattern of Land Cover Change Using Remotely Sensed Imagery and GIS: A Case Study of Omo-Shasha-Oluwa Forest Reserve, SW Nigeria (1986-2002). Journal of Geographic Information System, 6: 375-385.

Aris, F.P. and George, C. (2008). Morphology of the hair in the Goat breed Capra prisca. Journal of Animal and Veterinary Advances, 7(9): 1142-1145.

Bhat, M.A., Awadh, B.S., Aijaz, A.D. and Syed, W.B. (2014). Studies on Hair of Some Wild Animals for Species Identification as an Aid to Wildlife Forensics. International Journal for Agro Veterinary and Medical Sciences, 8(1): 2-5. 
Carlos, C.A., Bruno, H.S., Fernando, F. and Pedro, M.G. (2017). Comparing hairmorphology and molecular methods to identify fecal samples from Neotropical felids. PLOS ONE ,12(9):e0184073

Chernova, O.F. (2003). Architectonic and Diagnostic Significance of Hair Cortex and Medulla.Biology Bulletin, 30: 53-62.

Chiron, F., Hein, S., Chargé, R., Julliard, R., Martin, L., Roguet, A. and Jacob, J. (2018). Validation of hair tubes for small mammal population studies, Journal of Mammalogy, 99(2):478-485.

Cornally, A. and Lawton, C. (2016). A guide to the identification of Irish mammal hair.National Parks and Wildlife Service, Department of the Arts, Heritage, Regional, Rural and Gaeltacht Affairs, Ireland. Irish Wildlife Manuals, 92: 140.

Crocker, E.J. (1998). A new technique for the rapid simultaneous examination of medullae and cuticular patterns of hairs. Microscope, 46(3): 169-173.

Deedrick, D.W. and Koch, S.L. (2004). Microscopy of Hair Part I: A practical guide and manual for animal hairs. Forensic Science Community, 6(1):1-45.

Farag, M.F., Ghoniem, M.H., Abou-Hadeed, A.H. and Dhama, K. (2015). Forensic Identification of some Wild Animal Hair using Light and Scanning Electron Microscopy. Advances in Animal and Veterinary Sciences, 3 (10): 559-568. DOI:10.14737/journal.aavs/2015/3.10.559.568

Houck, M.M., Bisbing R, Watkins T.G. and Harmon R.P. (2004). The Science of Forensic Hair Comparisons and the Admissibility of Hair Comparison Evidence: Frye and Daubert Considered. Modern Microscopy Journal, 7-10.

Kitpipit, T. and Thanakiatkrai, P. (2013). Tiger hair morphology and its variations for wildlife forensic investigation. Maejo International Journal of Science and Technology, 7(3):433-443.

Linacre, A. and Tobe, S.S. (2011). An overview to the investigative approach to species testing in wildlife forensic science. Investigative Genetics, 2: 2-9.

Olaleru, F., Olugbebi, T.R., and Fasona, M.I. (2020). Morphological Studies on the Guard Hair of the Mona Monkey (Cercopithecus mona) in Omo-Shasha-Oluwa Forest Reserves of Southwest Nigeria. Egyptian Academic Journal of Biological Sciences (B. Zoology), 12(2): 15-23.

Phoebus, I., Boulanger, J., Eiken, Hans, G., Fløystad, I., Graham, K. Snorr, H., Anja, S. and Gordon, S. (2020). Comparison of grizzly bear hair-snag and scat sampling along roads to inform wildlife population monitoring. Wildlife Biology: wlb.00697.

Priyanka, N., Anupam, B., Komal, Y., Mahipal, S.S. and Rajendra, S. (2017). Comparison of different Animal Species Hairs with respect to their Medullary Index for the Individual Identification and comparison from the Animals of local Village of Palam Vihar, Gurugram, Haryana. International Journal of Recent Research and Applied Studies, 4(12): 6.

Sahajpal, V., Goyal, S.P., Jayapal, R., Yoganand, K. and Thakar, M.K. (2008). Hair characteristics of four Indian bear species. Science and Justice, 48: 8-15.

Sari, A. and Arpacik, A. (2018). Morphological hair identification key of common mammals in Turkey. Applied Ecology and Environmental Research, 16(4): 4593-4603.

Sato, H. (2002). Statistical evaluation of morphological data of Japanese head hair and the screening of evidential hair samples by cluster analysis. Journal of Legal Medicine, 4: 90-10. 
Sato, H., Matsuda, H., Kubota, S. and Kawano, K. (2006). Statistical comparison of dog and cat guard hairs using numerical morphology. Journal of Forensic Science International, 185: 94-103.

Sheela, V., Purushotham, G., Kumar, P. and Lakshman, M. (2018). Anatomical Studies on Hair Shaft of Blackbuck. International Journal of Pure and Applied Bioscience, 6(6):107-112.

Souza, F.C. and Azevedo, F.C.C. (2021). Hair as a tool for identification of predators and prey: A study based on scats of jaguars (Panthera onca) and pumas (Puma concolor). Biota Neotrop, 21(1):Doi.org/10.1590/1676-0611-BN-2020-1044

Tremori, T.M., Garcia, F.M.M., Florez, L.M.M., Goncalves, B.P., de Camargo, B.W.D.F., Gwinnett, C., Teixeira, C.R. and Rocha, N.S. (2018). Hair Analysis of Mammals of Brazilian Wildlife for Forensic Purposes. Open Journal of Animal Sciences, 8: 335-345.

Tridico, S.R. (2015). Morphological and molecular approaches to characterise modifications relating to mammalian hairs in archaeological, paleontological and forensic contexts. PhD Thesis submitted to the School of Veterinary and Life Sciences, Murdoch University 1: 1-173.

Verma, K. and Joshi, B. (2012). Different Animal Species Hairs as Biological Tool for the Forensic Assessment of Individual Identification Characteristics from Animals of Zoological Park, Pragti Maidan, New Delhi, India. Journal of Forensic Research,3(160): 2157-7145.

Walker, C.S., Walker, K.K., Paulo, G. and Pusey, A.E. (2018). Morphological Identification of Hair Recovered from Feces for Detection of Cannibalism in Eastern Chimpanzees. Folia Primatology, 89:240-250.

Yasser, A.A., Safwat, A. and Ahmed, G. (2018). Hair histology as a tool for forensic identification of some domestic animal species. Experimental and Clinical Sciences, International Journal, 17:663-670. 